\title{
A randomized clinical trial of neurally adjusted ventilatory assist versus conventional weaning mode in patients with COPD and prolonged mechanical ventilation
}

\author{
This article was published in the following Dove Press journal: \\ International Journal of COPD \\ II May 2016 \\ Number of times this article has been viewed
}

\section{Nai-Ying Kuo ${ }^{1,2}$ \\ Mei-Lien Tu',3 \\ Tsai-Yi Hung' \\ Shih-Feng $\mathrm{Liu}^{4}$ \\ Yu-Hsiu Chung ${ }^{4}$ \\ Meng-Chih $\operatorname{Lin}^{4}$ \\ Chao-Chien $\mathrm{Wu}^{4}$}

'Department of Respiratory Therapy,

Kaohsiung Chang Gung Memorial

Hospital; ${ }^{2}$ Kaohsiung Medical

University; ${ }^{3}$ Respiratory Care, Chang

Gung University of Science and

Technology, Chiayi, Taiwan; ${ }^{4}$ Division of Pulmonary and Critical Care Medicine,

Department of Internal Medicine,

Kaohsiung Chang Gung Memorial

Hospital and Chang Gung University

College of Medicine, Kaohsiung, Taiwan
Correspondence: Shih-Feng Liu Division of Pulmonary and Critical Care Medicine, Department of Internal Medicine, Kaohsiung Chang Gung Memorial Hospital and Chang Gung University College of Medicine, 123 Ta-Pei Road, Niaosong District, Kaohsiung, 8330I, Taiwan Tel +886 7 73। 7123 ext 8199 Email m85d@cgmh.org.tw
Background: Patient-ventilator asynchrony is a common problem in mechanically ventilated patients; the problem is especially obvious in COPD. Neutrally adjusted ventilatory assist (NAVA) can improve patient-ventilator asynchrony; however, the effect in COPD patients with prolonged mechanical ventilation is still unknown. The goals of this study are to evaluate the effect of NAVA and conventional weaning mode in patients with COPD during prolonged mechanical ventilation.

Methods: The study enrolled a total of 33 COPD patients with ventilator dependency for more than 21 days in the weaning center. A diaphragm electrical activity (Edi) catheter was inserted in patients within 24 hours after admission to the respiratory care center, and patients were randomly allocated to NAVA or conventional group. A spontaneous breathing trial was performed every 24 hours. The results correlated with the clinical parameters.

Results: There were significantly higher asynchrony incidence rates in the whole group after using Edi catheter (before vs post-Edi catheter insertion $=60.6 \%$ vs $87.9 \%, P<0.001$ ). Asynchrony index: before vs post-Edi catheter insertion $=7.4 \% \pm 8.5 \%$ vs $13.2 \% \pm 13.5 \%, P<0.01$. Asynchrony incidence: NAVA vs conventional $=0 \%$ vs $84.2 \%, P<0.001$. Asynchrony index: NAVA vs conventional $=0$ vs $11.9 \pm 11.2$ (breath $\%$ ), $P<0.001$. The most common asynchrony events were ineffective trigger and delayed trigger.

Conclusion: Compared to conventional mode, NAVA mode can significantly enhance respiratory monitoring and improve patient-ventilator interaction in COPD patients with prolonged mechanical ventilation in respiratory care center.

Keywords: Edi catheter, NAVA (neurally adjusted ventilatory assist), prolonged mechanical ventilation, asynchrony index, $\mathrm{COPD}$, pneumatic trigger

\section{Background}

In patients with COPD, the process of weaning from mechanical ventilation is frequently complicated and prolonged by physiological and psychological circumstances. The reported rate of weaning failure in COPD is very high, approximately $61 \%$, and as a result, in observed cases, there is $46 \%-59 \%$ prolonged invasive mechanical ventilation. ${ }^{1,2}$ Asynchrony is a particular problem in patients with mechanical ventilation and noninvasive mechanical ventilation, ${ }^{3,4}$ with a reported incidence between $10 \%$ and $88 \%$ during assisted mechanical ventilation. ${ }^{3}$ Patients with COPD commonly experience asynchrony, primarily due to intrinsic positive end-expiratory pressure (PEEP), air trapping, expiratory flow limitation, excessive sedation, and suboptimal 
ventilator settings during assisted mechanical ventilation. Asynchrony is also associated with prolonged mechanical ventilation, longer intensive care unit stay, mortality, and respiratory muscle dysfunction; and air leaks are also a major cause of asynchrony during noninvasive ventilation. ${ }^{5-9}$

Two recent studies found an incidence of asynchrony in $25 \%-40 \%$ of patients on ventilatory assistance. They also found that an asynchrony index $>10 \%$ is associated with a significantly prolonged time on ventilatory assistance. ${ }^{10,11}$ In contrast to the findings of Thille and Brochard, De Wit et al, and Chao et al, in the patient group with asynchrony, only $16 \%$ were successfully weaned, while $57 \%$ in the group without asynchrony were successfully weaned. ${ }^{11-13}$ In addition, another study by Doorduin et al also demonstrated that poor synchrony (timing errors above $20 \%$ between neural drive and pneumatic timing; NeuroSync index) is associated with the number of wasted efforts, which increases the work of breathing and causes NIV failure; worst case scenario will mean intubation in patients with COPD. ${ }^{5}$

Traditional pneumatic modes used for mechanical ventilation are fixed on the basis of pressure and flow within the airways. Unlike the traditional pneumatic modes, neutrally adjusted ventilatory assist (NAVA) is a spontaneous mode, which triggers, cycles, and regulates gas delivery based on the diaphragmatic electromyography signal via a specially designed nasogastric tube (diaphragm electrical activity [Edi]). ${ }^{14-16}$ The level of ventilatory assistance is proportional to the patient's breathing effort, there is no influence of autoPEEP during the ventilator cycle, since the assistance starts with the patient's breathing effort, and there should not be any influence from leaks during NIV due to better patientventilator interaction. ${ }^{14,17}$

Several studies have compared pneumatic modes (pressure support) to NAVA, with the majority of studies showing that NAVA improves patient-ventilator interaction, diaphragm efficiency, patient comfort (through synchrony), and sleep quality by increasing the slow-wave sleep. Moreover, NAVA can avoid the risk of excessive assistance and reduced ventilatory drive, and improve physiological parameters, with the delivery of lung protective tidal volumes while allowing patients to breathe spontaneously. ${ }^{16,18-23}$

This study hypothesizes that in patients with severe COPD who underwent prolonged mechanical ventilation, NAVA will improve weaning outcome compared to conventional weaning methods by improving patient-ventilator interaction. To date, no clinical studies have been published about the effectiveness of NAVA in COPD patients with prolonged mechanical ventilation. The goal of this study is to compare the effect of NAVA to conventional mode in a randomized controlled trial in patients with severe COPD.

\section{Patients and methods}

This study was designed as a prospective, randomized, controlled clinical study to determine the weaning efficacy of NAVA vs conventional modes in patients with COPD who endured weaning failure for more than 21 days. The clinical trial registration number is CMRPGB0382. The study enrolled a total of 37 COPD patients with prolonged mechanical ventilation in the respiratory care center (RCC) of Chang Gung Memorial Hospital between June 2012 and October 2014. This work was performed at Kaohsiung Chang Gung Memorial Hospital, Taiwan. The study was approved by the institutional review board of Chang Gung Memorial Hospital (IRB: 104-09970) and informed consent was obtained from the next of kin prior to start of the study. Inclusion criteria were: 1) older than or equal to 45 years with an established diagnosis of COPD, and 2) mechanical ventilation via intubation or tracheotomy, $>21$ days. Exclusion criteria were: 1) consent refused, 2) hemodynamic instability, 3) unable to breathe spontaneously, 4) poor short-term prognosis (defined as a high risk of death within 3 months), and 5) contraindications to the insertion of a nasogastric tube (such as face and nose fracture, recent nose surgery, esophageal obstruction).

After admission to the RCC, all patients were ventilated with a SERVO-i (Maquet, Solna, Sweden), with a clinician-set pressure support level or assist-control. An Edi catheter was inserted within 24 hours if the patient met the inclusion criteria and did not meet any of the exclusion criteria. The breathing capability of the patient was then tested by confirming a stable Edi signal $>2 \mu \mathrm{V}$. If the Edi signal remained below this level, the ventilatory assistance has to decrease $30 \%$ and observe for 10 minutes. After decreasing the ventilatory $30 \%$ for 10 minutes and the Edi signal was still below $2 \mu \mathrm{V}$, or end-tidal $\mathrm{CO}_{2}$ reached $60 \mathrm{mmHg}$, the patient was excluded from the study and previous settings were restored. If the Edi signal was still below $2 \mu \mathrm{V}$, the patient was excluded from the study and previous settings were restored. Patients able to trigger the ventilator were then randomized to two groups: NAVA and conventional mode. A spontaneous breathing trial (SBT) was performed every 24 hours if the patient met the following criteria: 1) no fever or infection, 2) hemodynamic stability, 3) fraction of inspired oxygen $\left(\mathrm{FiO}_{2}\right)<50 \%$, and 4) $\mathrm{PEEP}<8 \mathrm{cmH}_{2} \mathrm{O}$. The SBT was performed with a PEEP of $5 \mathrm{cmH}_{2} \mathrm{O}$ and pressure-support ventilation (PSV) level of $8 \mathrm{cmH}_{2} \mathrm{O}$. If the SBT was successful, the patient was evaluated for extubation and noninvasive ventilation. If the patient failed 
the SBT, he was returned to assisted ventilation with a NAVA setting corresponding to $50 \%$ of the peak Edi level during the SBT. The PSV group was returned to a PSV level mandated by the conventional weaning protocol.

Asynchrony events were obtained from the Edi signal and ventilator graphic waveform. The asynchrony index was calculated by comparing the Edi to the flow waveform during 1 minute. The primary outcomes of the study were to establish the detection rate of asynchrony events using waveform analysis or Edi, respectively, and to evaluate the weaning outcome in COPD patients with prolonged mechanical ventilation using NAVA or conventional weaning mode. The secondary outcomes included total length of mechanical ventilation, the length of RCC stay, hospital stay, and mortality rate after 90 days.

\section{Data analysis}

Data collection was performed before Edi catheter insertion, post-Edi catheter insertion, after randomization and implementation of the SBT every 24 hours. Data collection included demographic data, prognostic scores, and ventilator and hemodynamic values. Descriptive statistics were expressed as mean \pm standard deviation or median and interquartile range depending on the nature and distribution of the variables. Variables normally distributed were compared by the Student's $t$-test. For variables without a normal distribution, the Mann-Whitney $U$ rank test was used for comparison. Categorical variables were compared using Fisher's exact test. For all comparisons, a difference of $P<0.05$ was considered statistically significant. All analyses were performed using SPSS 17.0 software.

\section{Results}

We included 37 COPD patients with ventilator dependency for more than 21 days, from June 2012 to October 2014. Four patients were excluded from the analysis due to hemodynamic instability. Flowchart of registered patients was presented in Figure 1. The demographic and patient

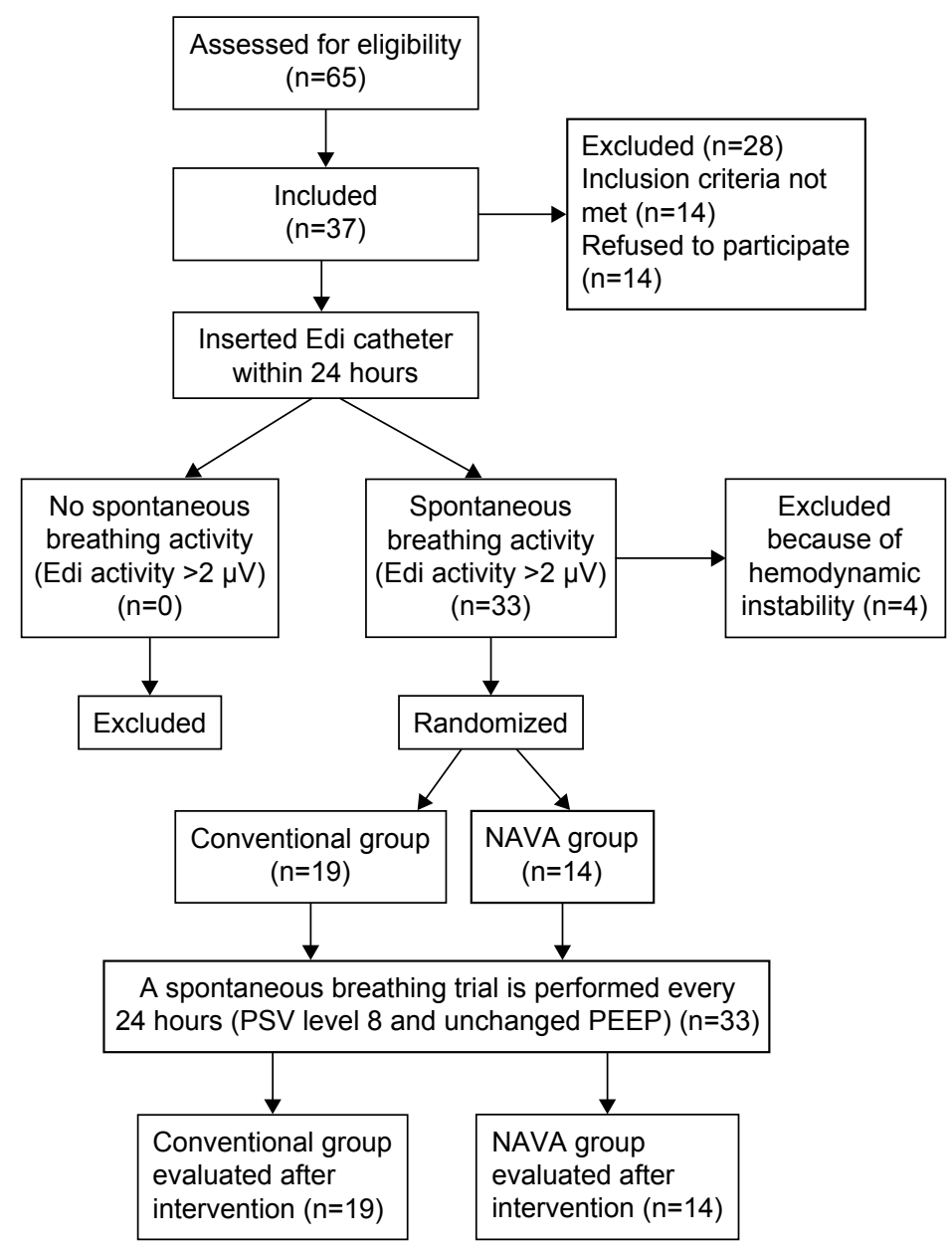

Figure I Flowchart of registered patients.

Abbreviations: NAVA, neurally adjusted ventilatory assist; PSV, pressure-support ventilation; Edi, diaphragm electrical activity; PEEP, positive end-expiratory pressure. 
characteristics were presented in Table 1. Clinical data were collected during three different periods: T0: immediately after Edi catheter insertion, T1: after intervention, and T2: at the end of the SBT trial (Table 2).

After admission to the RCC, an Edi catheter was inserted in all study subjects within 24 hours. Asynchrony recognition rates before and after Edi catheter insertion were described in Figure 2. Asynchrony incidence diagnosed without Edi catheter was $60.6 \%$ and after Edi catheter insertion was $87.9 \%(P<0.001)$. Asynchrony index without Edi catheter was $7.4 \%$ and after Edi catheter insertion was $13.2 \%$ $(P<0.01)$. The asynchrony events calculated from the flow waveforms and Edi signals, respectively, were: ineffective trigger $30.3 \%$ vs $54.5 \%(P<0.005)$; delayed trigger $6.1 \%$ vs $27.2 \%(P<0.008)$; flow asynchrony $6.1 \%$ vs $18.1 \%$ $(P<0.04)$; double triggering $9.1 \%$ vs $18.1 \%(P<0.08)$; auto

Table I Patient characteristics

\begin{tabular}{|c|c|c|c|}
\hline Variables & $\begin{array}{l}\text { NAVA } \\
(n=\mid 4)\end{array}$ & $\begin{array}{l}\text { Conventional } \\
(n=19)\end{array}$ & $P$-value \\
\hline \multicolumn{4}{|l|}{ Sex $n(\%)$} \\
\hline Male & II (78.6\%) & $13(68.4 \%)$ & 0.51 \\
\hline Female & $3(21.4 \%)$ & $6(31.6 \%)$ & \\
\hline Age, years & $79.3 \pm 6.2$ & $76.9 \pm 9.3$ & 0.62 \\
\hline IBW $(\mathrm{Kg})$ & $53.6 \pm 11.2$ & $55.7 \pm 1.7$ & 0.82 \\
\hline Total ICU, days & $19.4 \pm 11.8$ & $22.3 \pm 19.4$ & 0.08 \\
\hline Ventilator days before & $26.9 \pm 10.7$ & $27.1 \pm 13.0$ & 0.41 \\
\hline \multicolumn{4}{|l|}{ PFT (before admission) } \\
\hline FEV,/Pred (\%) & $59.0 \pm 15.5$ & $53.5 \pm 16.5$ & 0.51 \\
\hline $\mathrm{FEV}_{1} / \mathrm{FVC}(\%)$ & $64.8 \pm 18.8$ & $71.9 \pm 17.7$ & 0.12 \\
\hline SOFA score & $3.7 \pm 2.8$ & $4.3 \pm 2.5$ & 0.32 \\
\hline \multicolumn{4}{|l|}{ APACHE II } \\
\hline Mean & $17.4 \pm 4.1$ & $18.7 \pm 5.0$ & 0.42 \\
\hline$\geq 15$ & $10(71.4 \%)$ & $15(78.9 \%)$ & 0.59 \\
\hline \multicolumn{4}{|l|}{ Acute lung injury } \\
\hline Sepsis & $0(0 \%)$ & $15.3 \%$ & 0.38 \\
\hline Bacterial pneumonia & $6(42.9 \%)$ & $6(31.6 \%)$ & 0.50 \\
\hline \multicolumn{4}{|l|}{ ICU ventilator data } \\
\hline $\mathrm{TV}(\mathrm{mL})$ & $415.9 \pm 128.7$ & $511.0 \pm 79.9$ & 0.02 \\
\hline TV of IBW (mL/kg) & $6.8 \pm 1.9$ & $9.4 \pm 1.4$ & 0.01 \\
\hline $\mathrm{RR}$, breath/min & $23.3 \pm 5.5$ & $19.7 \pm 6.4$ & 0.05 \\
\hline$M V(L)$ & $9.0 \pm 2.7$ & $9.3 \pm 2.3$ & 0.89 \\
\hline RSBI & $64.1 \pm 28.9$ & $80.9 \pm 38.0$ & 0.42 \\
\hline \multicolumn{4}{|c|}{ Respiratory muscle strength } \\
\hline MIP $\left(\mathrm{cmH}_{2} \mathrm{O}\right)$ & $22.9 \pm 9.3$ & $26.4 \pm 9.0$ & 0.35 \\
\hline $\operatorname{MEP}\left(\mathrm{cmH}_{2} \mathrm{O}\right)$ & $25.5 \pm 14.3$ & $26.9 \pm 18$ & 0.73 \\
\hline \multicolumn{4}{|l|}{ Nutrition } \\
\hline ALB $(3.5-5 \mathrm{~g} / \mathrm{dL})$ & $2.6 \pm 9.3$ & $2.7 \pm 9.3$ & 0.68 \\
\hline
\end{tabular}

Notes: Pearson chi-square test was used for sex, Student's $t$-test was used for age, body weight, total ICU days, ventilator days before included, and nonparametric method for APACHE II and nutrition. Data is presented as either $n(\%)$ or mean \pm SD. Abbreviations: IBW, ideal body weight; PFT, pulmonary function test; TV, tidal volume; RR, respiratory rate; $M V$, minute volume; RSBI, rapid shallow breathing index; MIP, maximum inspiratory pressure; MEP, maximum expiratory pressure; NAVA, neutrally adjusted ventilatory assist; ICU, intensive care unit; $\mathrm{FEV}_{1} / \mathrm{pred}$, predicted forced expiratory volume in I second; $F E V_{1} / F V C$, forced expiratory volume in I second/forced vital capacity; APACHE II, Acute Physiology and Chronic Health Enquiry II; ALB, albumin; SOFA, Sequential Organ Failure Assessment. triggering $9.1 \%$ vs $15.1 \%(P<0.15)$, and delayed cycling $0 \%$ vs $3.0 \%(P<0.15)$.

Asynchrony classification and incidence for NAVA and conventional group were shown in Table 3. Asynchrony index in NAVA vs conventional mode was $0 \%$ vs $11.9 \%$ $(P<0.001)$; ineffective trigger $0 \%$ vs $52.6 \%(P<0.001)$; delayed trigger $0 \%$ vs $36.8 \%$ ( $P<0.001)$; flow asynchrony $0 \%$ vs $26.3 \%(P<0.001)$; and double triggering $0 \%$ vs $21.1 \%$ $(P<0.001)$. The main asynchrony events in this study were ineffective triggering (42.1\%), delayed trigger (31.6\%), flow

Table 2 Clinical data collection by T0, TI, T2 ${ }^{\mathrm{a}}$

\begin{tabular}{|c|c|c|c|c|c|}
\hline Variables & \multicolumn{2}{|c|}{$\begin{array}{l}\text { NAVA } \\
(n=14)\end{array}$} & \multicolumn{2}{|c|}{$\begin{array}{l}\text { Conventional } \\
(n=19)\end{array}$} & $P$-value \\
\hline \multicolumn{6}{|c|}{ T0: data immediately post-Edi catheter insertion } \\
\hline $\mathrm{TV}(\mathrm{mL})$ & 424.9 & \pm 102.4 & 448.9 & \pm 100.6 & 0.71 \\
\hline TV of IBW $(\mathrm{mL} / \mathrm{kg})$ & 7.1 & \pm 1.9 & 8.3 & \pm 1.9 & 0.09 \\
\hline $\mathrm{RR}$, breath/min & 22.3 & \pm 5.2 & 22.8 & \pm 7.3 & 0.21 \\
\hline$M V(L)$ & 9.7 & \pm 2.1 & 9.4 & \pm 2.1 & 0.78 \\
\hline TV/Edi (NVE) & 71.9 & \pm 41.9 & 92.9 & \pm 66.9 & 0.48 \\
\hline RSBI & 64.1 & \pm 28.9 & 80.9 & \pm 38.0 & 0.42 \\
\hline MIP $\left(\mathrm{cmH}_{2} \mathrm{O}\right)$ & 20.0 & \pm 1.0 & 20.5 & \pm 9.3 & 0.71 \\
\hline $\operatorname{MEP}\left(\mathrm{cmH}_{2} \mathrm{O}\right)$ & 14.0 & \pm 0.1 & 21.5 & \pm 10.6 & 0.46 \\
\hline PO.I, $\mathrm{cmH}_{2} \mathrm{O}$ & I.I & \pm 1.0 & 1.0 & $\pm I . I$ & 0.81 \\
\hline PEEPi, $\mathrm{cmH}_{2} \mathrm{O}$ & 2.3 & \pm 3.4 & 3.9 & \pm 3.7 & 0.27 \\
\hline $\operatorname{ALB}(3.5-5 \mathrm{~g} / \mathrm{dL})$ & 1.7 & \pm 1.5 & 2.4 & \pm 0.5 & 0.23 \\
\hline \multicolumn{6}{|c|}{ TI: data after intervention } \\
\hline \multicolumn{6}{|l|}{ Ventilator data } \\
\hline $\mathrm{TV}(\mathrm{mL})$ & 435.7 & \pm 109.3 & 463.3 & \pm 104.3 & 0.42 \\
\hline TV of IBW $(\mathrm{mL} / \mathrm{kg})$ & 7.2 & \pm 1.8 & 8.5 & \pm 1.8 & 0.05 \\
\hline $\mathrm{RR}$, breath/min & 26.0 & \pm 6.7 & 23.2 & \pm 8.7 & 0.23 \\
\hline$M V(L)$ & 10.5 & \pm 2.0 & 10.2 & \pm 3.2 & 0.68 \\
\hline TV/Edi (NVE) & 74.7 & \pm 54.9 & 89.5 & \pm 70.1 & 0.71 \\
\hline RSBI & 91.6 & \pm 57.9 & 127.1 & $\pm|4| .3$ & 0.55 \\
\hline $\operatorname{MIP}\left(\mathrm{cmH}_{2} \mathrm{O}\right)$ & 25.4 & \pm 12.6 & 26.0 & \pm 14 & 0.96 \\
\hline $\operatorname{MEP}\left(\mathrm{cmH}_{2} \mathrm{O}\right)$ & 32.0 & \pm 20.2 & 26.1 & \pm 24 & 0.21 \\
\hline PO.I, $\mathrm{cmH}_{2} \mathrm{O}$ & 1.2 & \pm 1.7 & I.I & \pm 0.9 & 0.84 \\
\hline PEEPi, $\mathrm{cmH}_{2} \mathrm{O}$ & 2.4 & \pm 4.9 & 2.7 & \pm 3.6 & 0.77 \\
\hline ALB $(3.5-5 \mathrm{~g} / \mathrm{dL})$ & 1.7 & \pm 1.5 & 2.4 & \pm 0.5 & 0.51 \\
\hline \multicolumn{6}{|c|}{ T2: data at the end of SBT trial } \\
\hline $\mathrm{TV}(\mathrm{mL})$ & 373.8 & \pm 80.9 & 391.6 & \pm 87.7 & 0.67 \\
\hline TV of IBW $(\mathrm{mL} / \mathrm{kg})$ & 6.1 & \pm 1.1 & 7.2 & \pm 1.6 & 0.05 \\
\hline $\mathrm{RR}$, breath/min & 24.7 & \pm 4.7 & 25.7 & \pm 8.7 & 0.87 \\
\hline $\mathrm{MV}(\mathrm{L})$ & 8.9 & \pm 2.1 & 9.4 & \pm 2.3 & 0.51 \\
\hline TV/Edi (NVE) & 54.0 & \pm 52.5 & 54.4 & \pm 49.9 & 0.86 \\
\hline RSBI & 104.6 & \pm 54.2 & 129.6 & \pm 120.7 & 0.87 \\
\hline $\operatorname{MIP}\left(\mathrm{cmH}_{2} \mathrm{O}\right)$ & 30.9 & \pm 12.6 & 26.7 & $\pm I I . I$ & 0.42 \\
\hline $\operatorname{MEP}\left(\mathrm{cmH}_{2} \mathrm{O}\right)$ & 31.6 & \pm 17.8 & 25.9 & \pm 23.2 & 0.16 \\
\hline $\operatorname{ALB}(3.5-5 \mathrm{~g} / \mathrm{dL})$ & 2.5 & \pm 0.7 & 3.0 & \pm 0.1 & 0.31 \\
\hline
\end{tabular}

Notes: aNonparametric method. Data presented as mean \pm standard deviation. Abbreviations: IBW, ideal body weight; NAVA, neutrally adjusted ventilatory assist; TV, tidal volume; RR, respiratory rate; MV, minute volume; RSBI, rapid shallow breathing index; MIP, maximum inspiratory pressure; MEP, maximum expiratory pressure; Edi, diaphragm electrical activity; NVE, tidal volume/neuro-ventilatory efficiency; PEEPi, intrinsic positive end-expiratory pressure; SBT, spontaneous breathing trial; ALB, albumin; $\mathrm{p} 0 . \mathrm{I}$, negative airway pressure generated during the first $100 \mathrm{msec}$ of an occluded inspiration. 


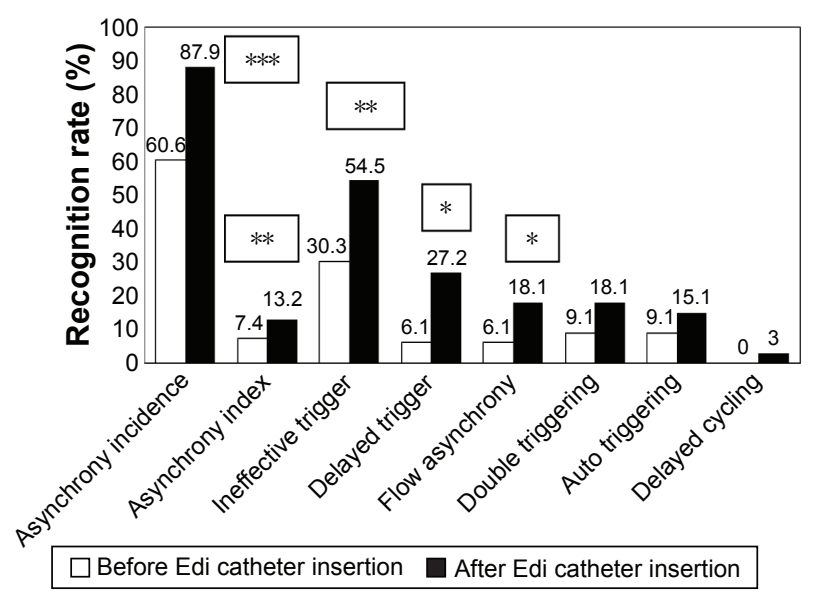

Figure 2 Asynchrony recognition rate before and after Edi catheter insertion. Notes: Frequencies and Pearson's chi-squared test. $* P<0.05 ; * * P<0.01$; $* * * P<0.001$. Abbreviation: Edi, diaphragm electrical activity.

asynchrony (26.3\%), and double triggering $(21.1 \%)$ in the conventional group. The asynchrony index was displayed in Figure 3 and the accumulated asynchrony numbers were displayed in Figure 4. Outcomes in the NAVA and control group were described in Table 4. Mortality rate in NAVA vs the control group in the RCC was $7.1 \%$ vs $31.6 \%(P=0.09)$; 90 -day mortality was $28.6 \%$ vs $31.6 \%(P=0.85)$; total RCC stay days were $20.3 \mathrm{~d} \pm 12.2 \mathrm{~d}$ vs $22.1 \mathrm{~d} \pm 21.1 \mathrm{~d}(P=0.78)$; and total ventilator days were $47.3 \mathrm{~d} \pm 28.8 \mathrm{~d}$ vs $49.2 \mathrm{~d} \pm 36.0$ $\mathrm{d}(P=0.94)$.

\section{Discussion}

The main finding of this study demonstrates that NAVA improves patient-ventilator interaction compared to conventional mode in COPD patients with prolonged mechanical ventilation. COPD patients with acute respiratory failure requiring mechanical ventilation have frequent episodes of patient-ventilator asynchrony. ${ }^{3,7,24}$ According to Thille et al and Thille and Brochard, one quarter of all patients had a high rate of asynchrony during assisted ventilation; interestingly,

Table 3 Asynchrony index between NAVA and control group $(n=33)$

\begin{tabular}{llll}
\hline Variables n(\%) & $\begin{array}{l}\text { NAVA } \\
(\mathbf{n}=\mathbf{I 4 )}\end{array}$ & $\begin{array}{l}\text { Conventional } \\
(\mathbf{n}=\mathbf{I 9 )}\end{array}$ & P-value \\
\hline Asynchrony index & 0 & $\mathrm{I} 6(84.2)$ & $<0.00 \mathrm{I}$ \\
Asynchrony incidence & 0 & $\mathrm{I} 6(84.2)$ & $<0.00 \mathrm{I}$ \\
Ineffective trigger & 0 & $\mathrm{I} 0(52.6)$ & $<0.00 \mathrm{I}$ \\
Delayed trigger & 0 & $7(36.8)$ & $<0.00 \mathrm{I}$ \\
Flow asynchrony & 0 & $5(26.3)$ & $<0.00 \mathrm{I}$ \\
Double triggering & 0 & $4(2 \mathrm{I} . \mathrm{I})$ & - \\
Auto triggering & 0 & $0 / 0$ & - \\
Premature cycling & 0 & $0 / 0$ & - \\
Delayed cycling & 0 & $0 / 0$ & \\
\hline
\end{tabular}

Abbreviation: NAVA, neurally adjusted ventilatory assist.

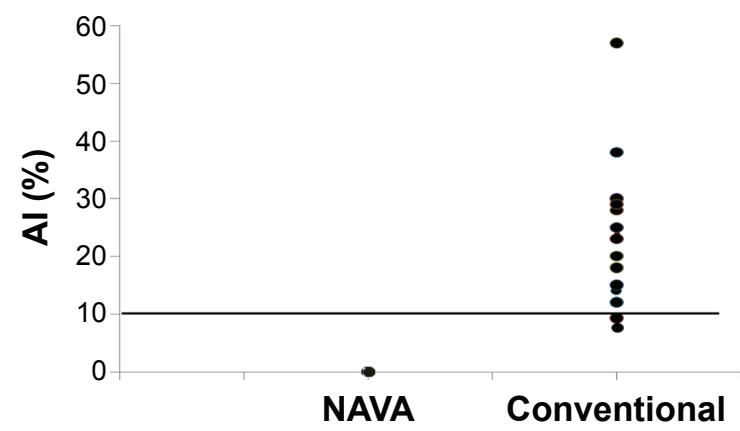

Figure 3 Asynchrony index of the all patients.

Notes: Filled circles indicate individual asynchrony index of each patient. Fourteen patients had $\mathrm{Al}>10 \%$ in the control group, but no patients had $\mathrm{Al}$ in NAVA mode. Abbreviations: NAVA, neurally adjusted ventilatory assist; $\mathrm{Al}$, asynchrony index.

the incidence of asynchrony was nearly $82 \%$ in patients who received PSV and $18 \%$ during assist-control ventilation. ${ }^{10,11}$ In our study, $80 \%(\mathrm{~N}=23)$ of the patients who were transferred to our RCC, had a high level of pressure support (PSV level $>15 \mathrm{cmH}_{2} \mathrm{O}$ ) or assist-control ventilation, and incidence of asynchrony was nearly $84 \%$ in the control group $(\mathrm{N}=16)$. This demonstrates that poor patient-ventilator interaction is a common problem in patients with COPD during invasive mechanical ventilation.

On the other hand, in our study, the Edi catheter could effectively provide a real-time demonstration of the degree of synchrony/asynchrony between the patient's diaphragmatic activity and the conventionally triggered assisted breath. ${ }^{25}$ Our asynchrony recognition rate after insertion of the Edi catheter was significantly different $(P<0.05)$, indicating that monitoring based on the Edi signal could increase the ability to recognize the rate and the type of asynchrony in difficult to wean patients. The benefit of the Edi signal is enhanced respiratory monitoring. Respiratory monitoring using the

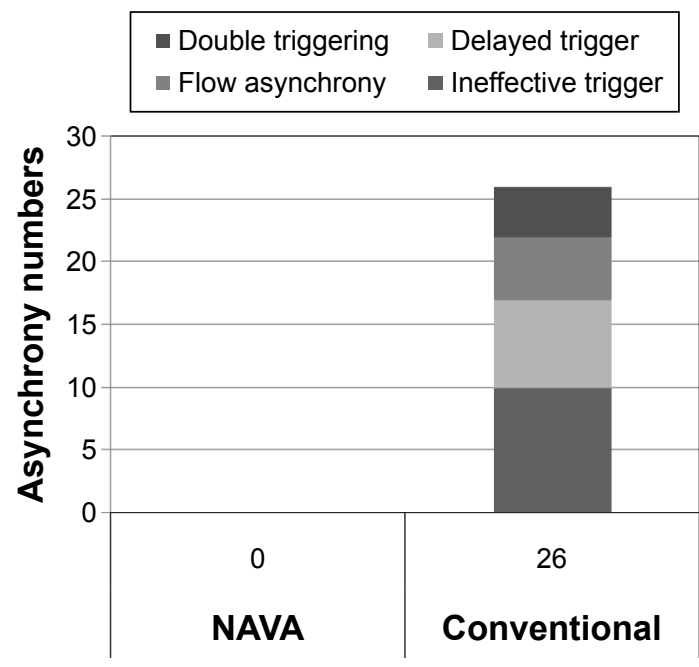

Figure 4 Accumulated asynchrony numbers of the NAVA and control group. Abbreviation: NAVA, neurally adjusted ventilatory assist. 
Table 4 Weaning outcome after NAVA and conventional mode

\begin{tabular}{|c|c|c|c|c|c|}
\hline \multirow{2}{*}{$\begin{array}{l}\text { Variables, total } \\
(\mathrm{n}=\mathbf{3 3}) \\
\text { RCC mortality }(\%)\end{array}$} & \multicolumn{2}{|c|}{ NAVA $(n=14)$} & \multicolumn{2}{|c|}{$\begin{array}{l}\text { Conventional } \\
(n=19)\end{array}$} & \multirow{2}{*}{$\begin{array}{l}P \text {-value } \\
0.09\end{array}$} \\
\hline & I & (7.1) & 6 & $(31.6)$ & \\
\hline 90 days mortality (\%) & 4 & $(28.6)$ & 6 & $(31.6)$ & 0.94 \\
\hline Total RCC days & 20.3 & \pm 12.2 & 22.1 & \pm 21.1 & 0.78 \\
\hline $\begin{array}{l}\text { Ventilator-free days in } \\
\text { I month }\end{array}$ & 11.6 & \pm 9.0 & 12.2 & \pm 9.4 & 0.84 \\
\hline Total ventilator days & 47.3 & \pm 28.8 & 49.2 & \pm 36.0 & 0.85 \\
\hline Total hospital days & 77.0 & \pm 40.0 & 71.7 & \pm 39.1 & 0.92 \\
\hline
\end{tabular}

Notes: Data were presented as either $\mathrm{n}(\%)$ or mean \pm SD.

Abbreviations: NAVA, neurally adjusted ventilatory assist; RCC, respiratory care center.

Edi signal not only increases the ability to recognize the rate and the type of asynchrony, but may also aid clinical staff in resolving problems earlier. ${ }^{26}$ Moreover, NAVA will improve patient-ventilator interaction owing to the fact that the pressure applied by the ventilator to the airway opening is proportional to the Edi signal. Sixty-nine percent $(\mathrm{N}=9)$ of patients in the NAVA group had better triggering after the change from conventional mode to NAVA mode.

Patients with COPD are regarded as particularly difficult to wean after prolonged mechanical ventilation, in our experience more than 21 days. ${ }^{27}$ Our patients were characterized by old age ( $>75$ years), high Acute Physiology and Chronic Health Enquiry (APACHE) II score (18.2 \pm 4.6 ), moderate obstructive pulmonary disease with multiple organ failure (Sequential Organ Failure Assessment [SOFA] Scale 4.1 \pm 2.5 ), and hypo-albuminuria (albumin [ALB] $<3 \mathrm{~g} / \mathrm{dL}$ ). In patients with COPD, the process of weaning from mechanical ventilation is frequently complicated and prolonged by physiological and psychological circumstances such as old age, poor lung function, expiratory flow limitation, air trapping, increased intrinsic PEEP, patient discomfort, dyspnea, and sleep fragmentation, leading to a prolonged weaning process. .1,28,29 $^{2}$

The weaning outcome and mortality in the NAVA group was better than the conventional group, although the weaning outcome was not significantly different, and some significant physiological results were also found in this study. Hence, further research should focus on enrolling a larger number of patients and recording some index of comfort in order to demonstrate better comfort than pneumatic modes and shorter weaning time in patients with COPD after prolonged mechanical ventilation.

\section{Limitations}

There is one major limitation in this study. Our study population was small and it was a single-center trial, hence, the result in weaning outcome is not statistically significant in this study. Although a better drive in NAVA mode, it could be improved if we measure index of comfort in this study.

\section{Conclusion}

Compared to conventional monitoring, Edi signal can significantly enhance respiratory monitoring, increasing the ability to recognize the rate and type of asynchrony. Compared to conventional pneumatic trigger, NAVA Edi trigger significantly improved patient-ventilator asynchrony, reduced work of breathing, and enhanced patient comfort by better synchrony in our COPD patients with prolonged mechanical ventilation. The NAVA mode also shows a trend in outcome benefit in the field of RCC mortality.

\section{Acknowledgments}

This study was supported by a grant from the Kaohsiung Chang Gung Memorial Hospital, Taiwan (CMRPGB0382). We are grateful to all the staff of the RCC who supported this project.

\section{Author contributions}

All authors contributed toward data analysis, drafting, and critically revising the paper, gave final approval of the version to be published, and agreed to be accountable for all aspects of work.

\section{Disclosure}

The authors report no conflicts of interest in this work.

\section{References}

1. Quinnell TG, Pilsworth S, Shneerson JM, Smith IE. Prolonged invasive ventilation following acute ventilatory failure in COPD: weaning results, survival, and the role of noninvasive ventilation. Chest. 2006;129(1):133-139.

2. Patthum A, Peters M, Lockwood C. Effectiveness and safety of Neurally Adjusted Ventilatory Assist (NAVA) mechanical ventilation compared to standard conventional mechanical ventilation in optimizing patient-ventilator synchrony in critically ill patients: a systematic review protocol. JBI Database System Rev Implement Rep. 2015;13(3): 31-46.

3. Jolliet P, Tassaux D. Clinical review: patient-ventilator interaction in chronic obstructive pulmonary disease. Crit Care. 2006;10(6):236.

4. Nava S, Pisani L. Neurally adjusted non-invasive ventilation in patients with chronic obstructive pulmonary disease: does patient-ventilator synchrony matter? Crit Care. 2014;18(6):670.

5. Doorduin J, Sinderby CA, Beck J, van der Hoeven JG, Heunks L. Automated patient-ventilator interaction analysis during neurally adjusted non-invasive ventilation and pressure support ventilation in chronic obstructive pulmonary disease. Crit Care. 2014;18(5):550.

6. de Wit M, Pedram S, Best AM, Epstein SK. Observational study of patient-ventilator asynchrony and relationship to sedation level. J Crit Care. 2009;24(1):74-80.

7. Epstein SK. How often does patient-ventilator asynchrony occur and what are the consequences? Respir Care. 2011;56(1):25-38. 
8. Sinderby C, Navalesi P, Beck J, et al. Neural control of mechanical ventilation in respiratory failure. Nat Med. 1999;5(12):1433-1436.

9. Branson RD, Blakeman TC, Robinson BR. Asynchrony and dyspnea. Respir Care. 2013;58(6):973-989.

10. Thille AW, Rodriguez P, Cabello B, Lellouche F, Brochard L. Patientventilator asynchrony during assisted mechanical ventilation. Intensive Care Med. 2006;32(10):1515-1522.

11. Thille AW, Brochard L. Promoting patient-ventilator synchrony. Clin Pulm Med. 2007;14(6):350-359.

12. De Wit M, Miller KB, Green DA, Ostman HE, Gennings C, Epstein SK Ineffective triggering predicts increased duration of mechanical ventilation. Crit Care Med. 2009;37(10):2740-2745.

13. Chao DC, Scheinhorn DJ, Stearn-Hassenpflug M. Patient-ventilator trigger asynchrony in prolonged mechanical ventilation. Chest. 1997; 112(6):1592-1599.

14. Lellouche F, Brochard L. Advanced closed loops during mechanical ventilation (PAV, NAVA, ASV, SmartCare). Best Pract Res Clin Anaesthesiol. 2009;23(1):81-93.

15. Barwing J, Ambold M, Linden N, Quintel M, Moerer O. Evaluation of the catheter positioning for neurally adjusted ventilatory assist. Intensive Care Med. 2009;35(10):1809-1814.

16. Sinderby C. Neurally adjusted ventilatory assist: insufficient evidence of broad clinical outcomes. Respir Care. 2013;58(11):e153-e154.

17. Sinderby C, Beck J. Neurally adjusted ventilatory assist: first indications of clinical outcomes. J Crit Care. 2014;29(4):666-667.

18. Diniz-Silva F, Moriya H, Alencar A, Amato M, Carvalho C, Ferreira J. Use of neurally adjusted ventilatory assist and pressure support ventilation to delivery protective mechanical ventilation in patients with acute respiratory distress syndrome: a randomized crossover clinical trial. Am J Respir Crit Care Med. 2015;191:A3898.
19. Demoule A, Clavel M, Rolland-Debord C, et al. Comparison of neurally adjusted ventilatory assist and pressure support ventilation during the early phase of weaning from mechanical ventilation - a randomized controlled study. Am J Respir Crit Care Med. 2015;191:A1189.

20. Spahija J, de Marchie M, Albert M, et al. Patient-ventilator interaction during pressure support ventilation and neurally adjusted ventilatory assist. Crit Care Med. 2010;38(2):518-526.

21. Delisle S, Ouellet P, Bellemare P, Tétrault JP, Arsenault P. Sleep quality in mechanically ventilated patients: comparison between NAVA and PSV modes. Ann Intensive Care. 2011;1(1):42.

22. Umbrello M, Formenti P. Ultrasonographic assessment of diaphragm function in critically ill subjects. Respir Care. Epub 2016 Jan 26.

23. Di Mussi, Spadaro S, Mirabella L, et al. Impact of prolonged assisted ventilation on diaphragmatic efficiency: NAVA versus PSV. Crit Care. 2016;20(1): 1 .

24. Powers SK, Wiggs MP, Sollanek KJ, Smuder AJ. Ventilator-induced diaphragm dysfunction: cause and effect. Am J Physiol Regul Integr Comp Physiol. 2013;305(5):R464-R477.

25. Navalesi P, Longhini F. Neurally adjusted ventilatory assist. Curr Opin Crit Care. 2015;21(1):58-64.

26. Rowley DD, Lowson SM, Caruso FJ. Diaphragmatic electrical activity signaling unmasks asynchrony and improves patient-ventilator interaction. Respir Ther. 2009;4:51-53.

27. Heunks LM, van der Hoeven JG. Clinical review: the ABC of weaning failure - a structured approach. Crit Care. 2010;14(6):245.

28. Mamary AJ, Kondapaneni S, Vance GB, Gaughan JP, Martin UJ, Criner GJ. Survival in patients receiving prolonged ventilation: factors that influence outcome. Clin Med Insights Circ Respir Pulm Med. 2011;5:17-26.

29. White AC. Long-term mechanical ventilation: management strategies. Respir Care. 2012;57(6):889-897.
International Journal of COPD

\section{Publish your work in this journal}

The International Journal of COPD is an international, peer-reviewed journal of therapeutics and pharmacology focusing on concise rapid reporting of clinical studies and reviews in COPD. Special focus is given to the pathophysiological processes underlying the disease, intervention programs, patient focused education, and self management protocols.

\section{Dovepress}

This journal is indexed on PubMed Central, MedLine and CAS. The manuscript management system is completely online and includes a very quick and fair peer-review system, which is all easy to use. Visit http://www.dovepress.com/testimonials.php to read real quotes from published authors. 